\title{
ORGANIC SELENIUM DELAY LIVER TUMOR GROWTH INDUCED BY DEN THROUGH MAINTAIN C-MET SIGNALING ON BALB-C MICE
}

\author{
ELALFY M. MAHMOUD $;$ IBRAHIM M. FOUDA ${ }^{* *}$ and MOHAMMED F. HAMED ${ }^{* * *}$ \\ ${ }^{*}$ Lecturer of Forensic and Toxicology Dept., Faculty of Veterinary Medicine Mansoura University. \\ ${ }^{* *}$ Lecturer of Biochemistry Dept., Faculty of Veterinary Medicine Mansoura University. \\ **** Lecturer of Pathology Dept Faculty of Veterinary Medicine, Mansoura University.
}

\section{ABSTRACT}

Received at: 3/9/2015

Accepted: 21/9/2015

\begin{abstract}
Notably, it was found that DEN accelerate liver tumor growth through enhanced cmet signaling loss while organic selenium delayed chemical carcinogenesis through maintaining hepatocyte growth factor receptor and improving antioxidant status of treated mice. Moreover selenium treated groups showed fewer and smaller foci and nodules than the DEN group. At the end of the experiment no mice showed hepatocellular carcinoma (HCC) in the DEN-Se group but showed only advanced dysplasia. While acontrol positive group which administered DEN showed hepatocellular carcinoma in all mice. Additionally, selenium maintained liver enzymes and antioxidant liver status to basal level while DEN enhanced significant increase of liver enzymes and significant decrease of super-oxide dismutase and glutathione levels to basal level. We conclude that selenium had an inhibitory effect on the initiation and promotion stages of DEN-induced preneoplastic foci and nodules. Selenium also prevented progression of these nodules to HCC.
\end{abstract}

Key words: HCC-selenium-HGF (Hepatocyte growth factor)-c-met (Hepatocyte growth factor receptor)-DEN (diethynitrosamine)-SOD1 (superoxide dismutase enzymes)

\section{INTRODUCTION}

The importance of hepatocellular carcinoma in Egypt is increased with elevation of the major risk factors of chronic liver infection with hepatitis B and hepatitis C viruses (Ezat et al., 2005) or aflatoxin (Anwar et al., 2008) while pesticides and schistosemiasis may enhanced occurrence of liver cancer (Badawi and Michael, 1999 and Ezat et al., 2005).

Based on data collected from international agency for research on cancer (IARC) (Ferlay et al., 2004) has found that cancer incidence and mortality in the world. The worldwide liver cancer deaths in 2002 was estimated as 598, 412 which constitute $9 \%$ of all cancer deaths and a third in site -specific cancer deaths, followed by lung and stomach cancer. Distribution of liver cancer was more serious among less developing countries. Notably, Liver cancer is the fifth most common cancer in men and the ninth in women. A detected 782,500 new liver cancer cases occurred in the world during 2012, with China alone accounting for about $50 \%$ of the total. Rates are more than twice as high in men as in women. Liver cancer rates are the highest in central america, west and central africa, and east and southeast asia (London WT, McGlynn KA., 2006).

It was reported that selenium could have a role in cancer treatment of different tissue like mammary gland (Helen et al., 1984), Colon (Kim et al., 2011) pancreatic (Aichler et al., 2007) prostate (Venkateswarah et al., 2004) and lung cancer (Fritz et al., 2011). Moreover, selenium may enhance the therapeutics efficacy of anti-cancer drugs like doxorubicin (Cao et al., 2004).

loss of c-met accelerate early stage of liver cancer in c-met conditional knockout transgenic mice treated by DENe (Takami et al., 2007), Loss of c-met accelerates development of liver fibrosis in response to $\mathrm{CCl} 4$ exposure through deregulation of multiple molecular pathways (Marquardt et al., 2012), deletion of the met tyrosine kinase in liver progenitor oval cells increased sensitivity to apoptosis in vitro (Xiao et al., 2001, Castillo et al., 2008) and lack of hepatocyte growth factor receptor (c-met) gene expression in fulminant hepatic failure livers before transplantation explained no response to exogenous hepatocyte growth factor (HGF) that could be 
maintain normal liver growth and regeneration (Trusolino et al., 2010).

C-met truncated transgenic mouse didn't show any neoplastic lesions along whole life span of mice (Amicone et al., 1995, 1997) while loss of c-metmade alteration of gene expression need for $\mathrm{g} 2 / \mathrm{m}$ phase progression during liver regeneration in mice (Factor et al., 2010), In contrast, c-met accelerate tumor growth in c-myc/ c-met double transgenic mouse model of liver cancer (Amicone et al., 2002). In consistent role of c-met in cancer, HGF/c-met mediates a proliferative advantage and promotes tumor invasion and metastasis (Navab et al., 2009).

Notably, N-acetyl-cysteine administration slowed tumor growth initiated by n-DEN in c-met deficient liver. At 3 months, the averages size of focal lesions in Metliv KO mice was reduced by 3 fold and reaches level found in Cre-ctrl mice when treated with $\mathrm{N}$ acetyl-cysteine. More over $\mathrm{N}$-acetyl-cysteine retain cmet receptor in treated mice (Takami et al., 2007).

The rational of this study to test if mechanism of selenium chemoprevention of liver tumor could be through maintaining c-met expression or not.

\section{MATERIALS and METHODS}

\section{Experimental animals:}

Male balb-c mice of $20 \mathrm{~g}$ and 8 weeks of age were obtained from the animal house of the medical research centre, faculty of medicine, Mansoura, Egypt. They were kept for 32 weeks under good ventilation and illumination conditions and allowed standard diet and water ad libitum. Mice were acclimatized for 2 weeks before experimental use.

\section{Treatment:}

DENe was purchased from Sigma Chemical Co. (St Louis, MO. USA). It was in the form of solution packaged in a $100 \mathrm{ml}$ serum bottle with butyl rubber stopper and aluminum tear steal. The bottle content was dissolved in $100 \mathrm{ml}$ saline to make a $1 \%$ solution. Tumor initiation was achieved by 6 times injection with DEN at a dose of $100 \mathrm{mg} / \mathrm{kg}$ b.w., twice dose every one weeks for 6 weeks according to (Shiota et al., 1999).

\section{Experimental design:}

The experimental animals were divided into four groups, each of ten rats as follows:

$1^{\text {st }}$ group: 6 Male Balb-c received diethyl nitrosamine at dose of $100 \mathrm{mg} / \mathrm{kg}$ twice per week for 6 weeks and kept on maintenance ration all long the experiment for 32 weeks.

$2^{\text {nd }}$ group: 6 Male Balb-c received diethyl nitrosamine at dose of $100 \mathrm{mg} / \mathrm{kg}$ twice per week for 6 weeks but kept on ration supported with selenium -1methionine ${ }^{*}$ at dose of $3 \mathrm{ppm}$ all long the experiment for 32 weeks.

$3^{\text {rd }}$ group: 6 male balb-c kept on ration supported with selenium -1-methionine at dose of $3 \mathrm{ppm}$.

$4^{\text {th }}$ group: 6 male balb-c kept on maintenance ration all long the experiment for 32 weeks.

After 6 week all groups kept for 32 weeks then mice weighted and sacrificed. Liver was examine grossly, weighted and divided into 2 parts: one preserved in buffered formalin saline $10 \%$ for histopathology, other was frozen -80 for biochemical and other molecular tests.

*Selenium -1-methionine: is brownish commercial substance add to concentrated ration at dose of $3 \mathrm{ppm}$ and mixed with ration in agriculture faculty research unit

\section{Histopathological study:}

Specimens from liver were fixed immediately in $10 \%$ neutral buffered formalin, dehydrated in different grades of alcohol, cleared in xylol, embedded in paraffin wax, sectioned at 4-6 $\mu$ thick and stained with Haematoxylin and Eosin (Bancroft et al., 1996) and examined microscopically.

\section{Biochemicalanalysis}

Blood was collected from each mice in a centrifuge tube and placed at room temperature for $20 \mathrm{~min}$. Serum was then separated by centrifugation at 3,000 rpm for $10 \mathrm{~min}$. Serum sample was divided into aliquots, one for determination of serum alanine transaminase (ALT), serum aspartate transaminase (AST) (Reitman and Frankel (1957).

Total glutathione content in liver samples was previously described by method of Anderson (1985) while SOD1 was determined according methods of Minami and Yoshikawa (1979).

RNA isolation, reverse transcription and RT-PCR The trizol reagent kit was used for total RNA isolation from cells. Reverse transcription was carried out using Superscript II reverse transcriptase. Primers that were used: c-met, 5GACTTCAGCCATCCCAATGT-3,3GGTGAACTTCTGCGTTTGC-5 (Gordin et al., 2010) and b-actin 5-ggcattgttaccaactgggacg-3, 3ctctttgatgtcacgcacgatttc-5. Moreover, Conditions for RT-PCR were as follows: $10 \mathrm{~min}$ at $95^{\circ} \mathrm{C}$ followed by $40-50$ cycles of $15 \mathrm{~s}$ at $95^{\circ} \mathrm{C}, 15 \mathrm{~s}$ at $60^{\circ} \mathrm{C}$, and $15 \mathrm{~s}$ at $72^{\circ} \mathrm{C}$. RT-PCR was performed as previously described (Luger et al., 2004).

\section{Statistical analysis:}

The results were statistically evaluated using Student's “t” test. (SPSS 2013). 


\section{RESULTS}

DEN slightly reduced the body weight while selenium maintains body weight similar to control group. Notably, DEN significantly increased liver weight and liver to body weight ratio when compared to other groups treated with selenium only or with DEN. Fig 1.

Notably selenium prevent progression of dysplasia into ultimate liver tumor which appeared grossly in DEN treated group (d) when compared with other groups treated with both selenium and DEN (c), selenium treated group (b) or control group which appeared normally (a). Figure 2.

Moreover, selenium appeared to maintain liver enzymes (AST, ALT) at basal level similar to control group while DEN treated group shown significantly increased of both AST and ALT when compared with control group. Additionally, selenium maintains antioxidant enzymes (SOD1 and total glutathione) while DEN treated group showed significantly reduced of both total glutathione and SOD1 when compared with control group. Figure 3.
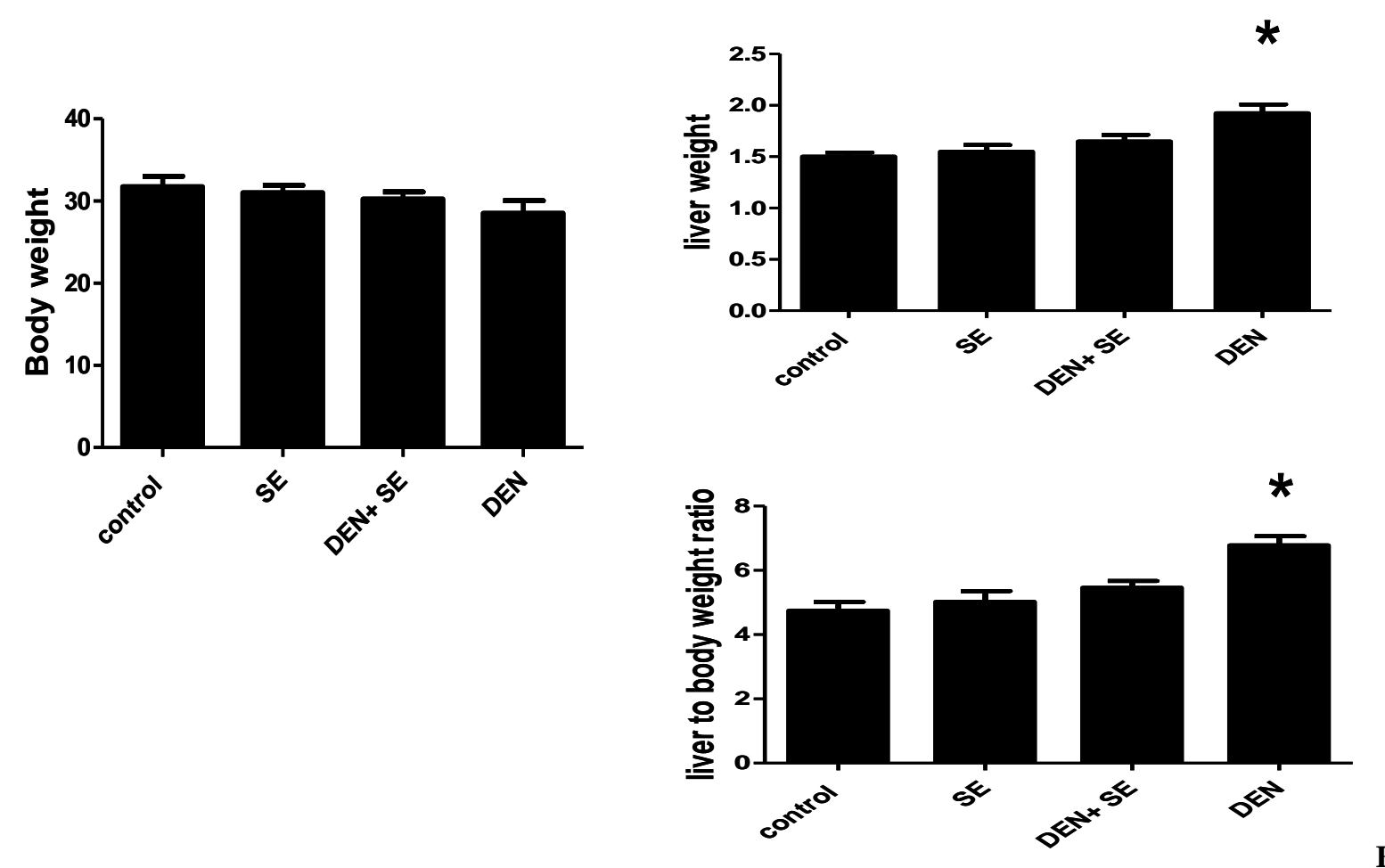

ig. 1: Showed that DEN slightly reduced the body weight while selenium retained body weight similar to control group. Notably, DEN significantly increased liver weight and liver to body weight ration
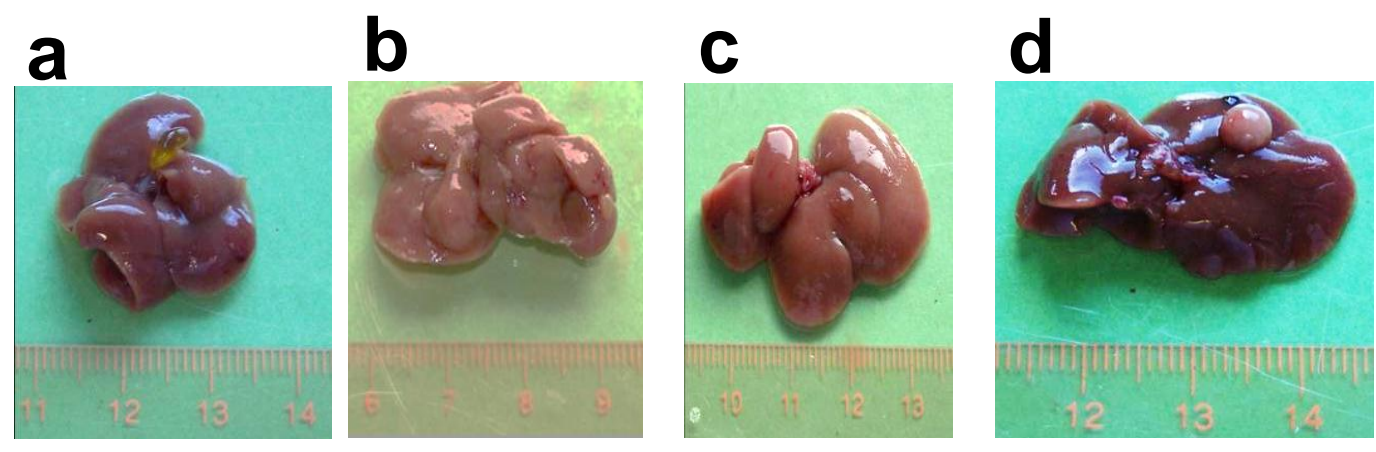

Fig. 2: Showed that liver treated with DEN show grossly liver tumor (d) while other group treated with both selenium and DEN when compared with other groups treated with both selenium and DEN (c), selenium treated group (b) or control group which appeared normally (a). 

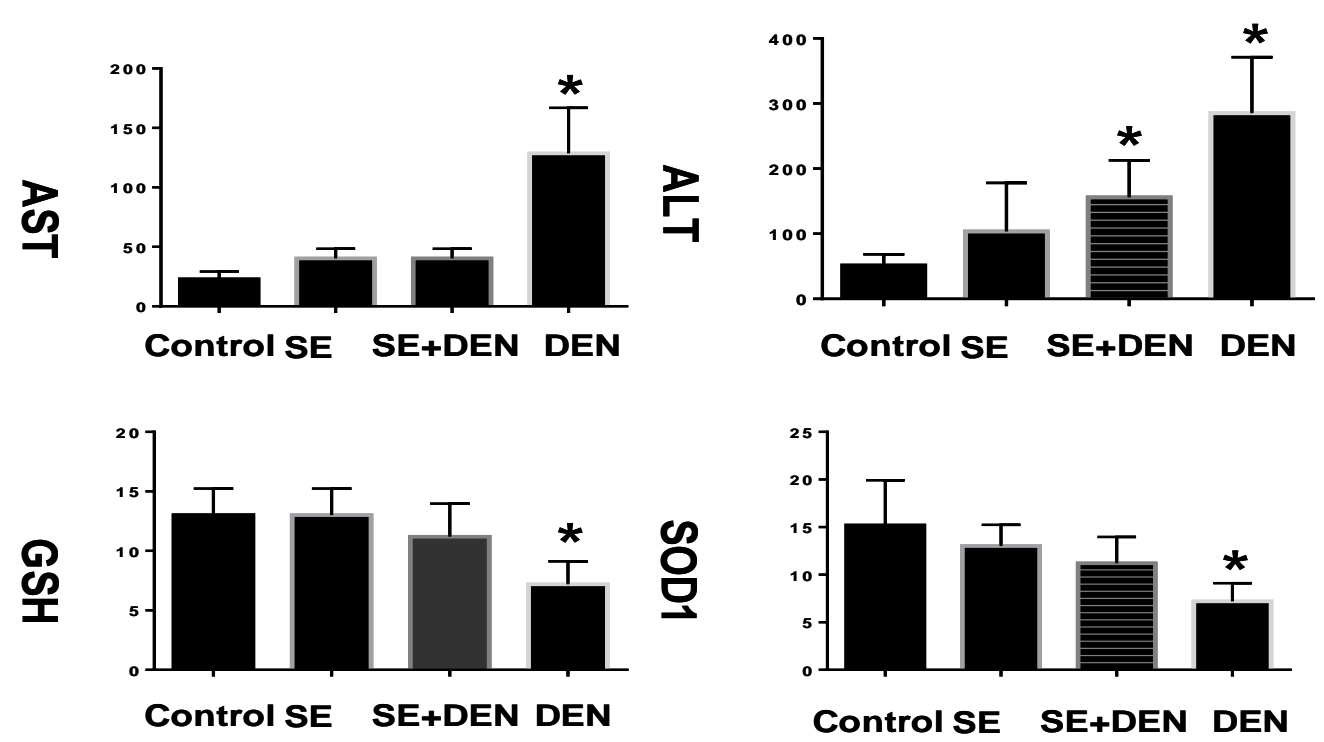

Fig. 3: Show that DEN treated group show significant increase of transaminase enzymes while reduced significantly both of antioxidant parameters. Selenium appears to slight increase of transaminase enzymes when compared with control. More over selenium maintain both SOD1 and total glutathione to basal level similar to control when treated with DEN.

Histopathology of liver treated with DEN showed increased activity of hepatocytes and progression to hepatocellular carcinoma with typical malignant criteria after 32 weeks of observation from DEN treatment. In contrast selenium maintain liver architecture with minimal hepatic dysplasia but only one mice out of 6 show dysplastic nodules and one small HCC. Group treated with selenium only show showing normal hepatocytes with normal hepatic architecture. While control group showed normal liver. Figure4

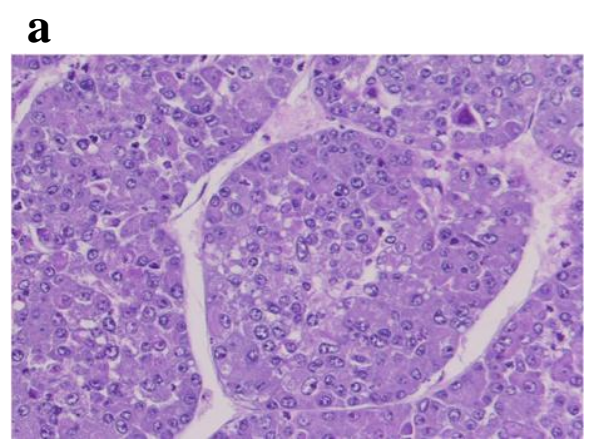

b

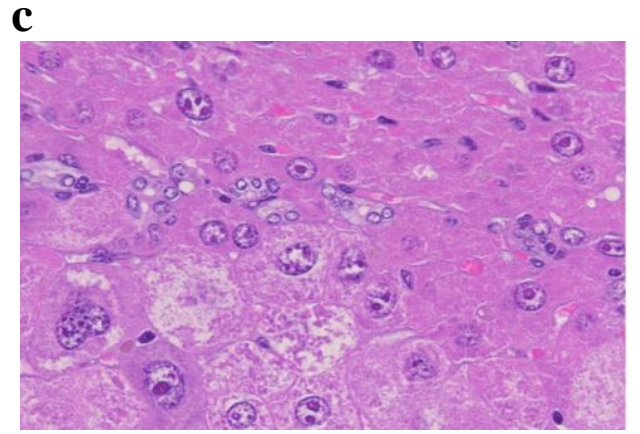

Fig. 4: (a) Group treated with DEN, Liver show progressive hepatocellular carcinoma when compared with control group which show normal liver architecture (b). While group treated with DEN +se show macrocytic dysplasia of hepatocytes indicated by enlarged nuclei with eosinophilic inclusions (c).

Notably DEN enhanced c-metm RNA expression loss while selenium and DEN+ SE groups maintain hepatocyte growth factor receptor (c-met) expression similar to control group. While B-actin show no change in all groups as b-actin consider house-keeping gene figure (5). 


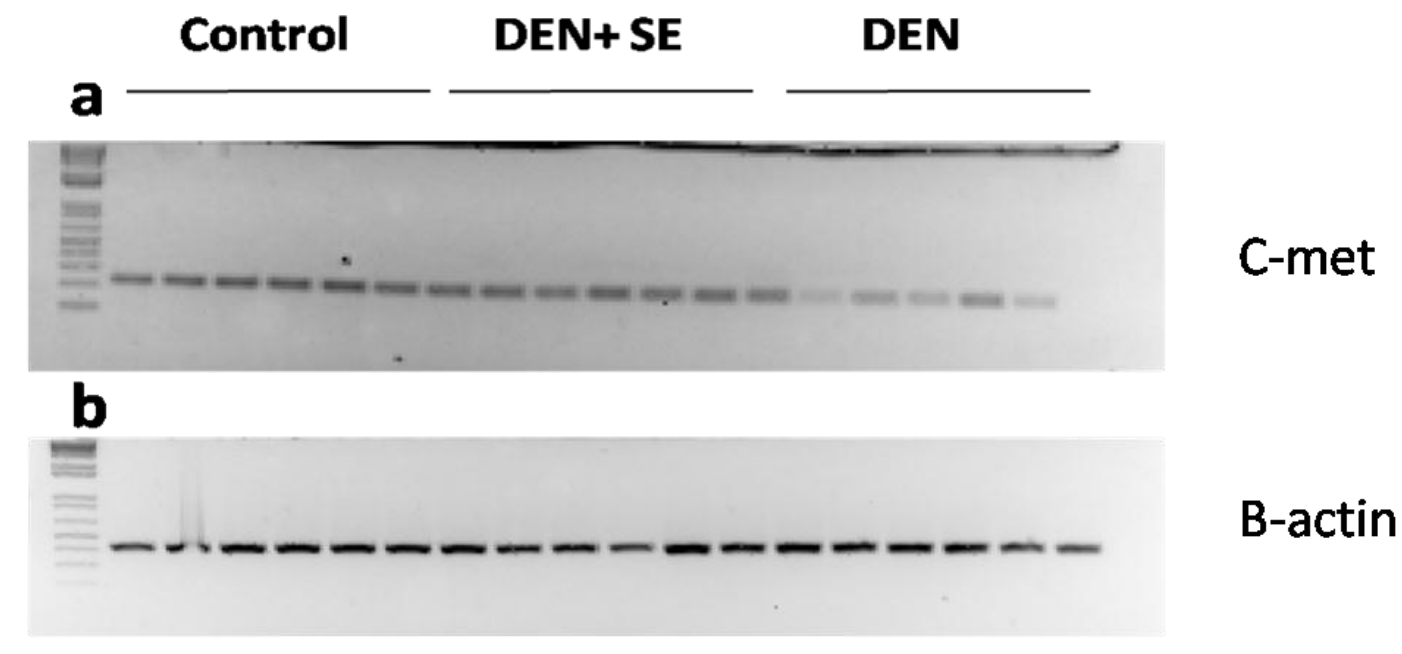

Fig. 5: DEN enhanced c-met gene expression loss (a) while selenium and DEN+ SE groups maintain c-met gene expression similar to control group. While B-actin show no change in all groups as b-actin consider housekeeping gene (b)

\section{DISCUSSION}

As shown by this study, selenium maintain, SOD1 and total glutathione was similar to control, redox microenvironment when treated with DEN. In other word selenium made its tumor suppressive power through modulation of the tumor redox microenvironment. SOD1 is the most important antioxidant enzyme that protects cells from ROS such as hydrogen peroxide and singlet oxygen species (Mates et al., 1999 and Sinha and Mimnaugh, 1990). ROS have the potential to create oxidative stress within cells that causes DNA damage, protein degradation, peroxidation of lipids, and finally leads to cell transformation or death based on ROS concentration. It is a well-documented fact that cancer cells are under high levels of oxidative stress compared with normal cells (Simon et al., 2000, Schumacker 2006 and Mizutani H., 2007).

Notably, selenium maintain hepatocyte growth factor rector (c-met) in mice treated with both selenium and DEN while DEN treated mice shown loss of c-met signaling. C-met reported to maintain liver body mass constant in c-met truncated transgenic mice (Amicone et al., 2002). Moreover, Takami et al. (2007) found that loss of c-met enhanced liver tumor growth in conditional knockout transgenic mice while these mice when treated with $\mathrm{N}$-acetyl-cysteine, slowed tumor growth initiated by n-nitrosodiethylamine in cmet deficient liver. At 3 months, the averages size of focal lesions in Metliv KO mice was reduced by 3 fold and reach level found in Cre-ctrl mice when treated with $\mathrm{N}$-acetyl-cysteine. More over $\mathrm{N}$-acetylcysteine retain c-metreceptor in treated mice.

In other words, there are correlations between c-met, redox microenvironment and anti-tumor effect of selenium. As most of the anticancer agents kill tumor cells by generating ROS or amplifying oxidative stress. We concluded that c-met expression and maintain redox microenvironment activity could elevate tumor chemo-sensitivity.

\section{REFERENCES}

Aichler, M.; Algül, H.; Behne, D.; Hölzlwimmer, G.; Michalke, B.; Quintanilla-Martinez, L.; Schmidt, J.; Schmid, RM. and Brielmeier, M. (2007): Selenium status alters tumor differentiation but not incidence or latency of pancreatic adenocarcinomas in Ela-TGF-alpha p53+/ mice. Carcinogenesis. Sep; 28(9): 20027.

Amicone Laura; Olivier Terradillos; Ludovica Calvo4; Barbara Costabile; Carla Cicchini; Carlo Della Rocca; Francesco Lozupone; Mauro Piacentini; Marie AnnickBuendia and Marco Tripodi (2002): Synergy between truncated c-met (cyto-Met) and c-Myc in liver oncogenesis: importance of TGF-b signalling in the control of liver homeostasis and transformation. Oncogene 21, $1335 \pm 1345$.

Anderson, ME. (1985): Determination of glutathione and glutathione disulfide in biological samples. Methods Enzymol 113: 548-555.

Anwer, WA.; Khaled, HM.; Amra, HA. and Elloffredo, CA. (2008): Changing pattern of hepatocelluer carcinoma and its risk factor on Egypt: possibilities for prevention. Mutat. Res. 659(1-2) 176-84.

Badawi, A.F. and Michael, M.S. (1999): Risk factors for hepatocelluer carcinoma in Egypt: the role of hepatitis-b viral infection and schistosomiasis. Anticancer res. (19(5c) 45659. 
Bancroft, D.; Stevens, A. and Turmer, R. (1996): Theory and practice of histological technique, 4thEd, Churchill Living Stone, Edinburgh, London, Melbourne.

Cao Shousng; Farukh A, Durrani and Youcef M. Rustum (2004): Selective modulation of theraputics efficacy of anticancer drugs by selenium containging compounds against human cancer clinical cancer research j. v102561-2569.

Castillo Gaelle del; ${ }^{*}$ Valentina M. Factor; ${ }^{\dagger}$ Margarita Fernández; ${ }^{*}$ Alberto Álvarez-Barrientos, ${ }^{*}$ Isabel Fabregat, ${ }^{\S}$ Snorri S. Thorgeirsson, ${ }^{\dagger}$ and Aránzazu Sánchez (2008): Deletion of the Met Tyrosine Kinase in Liver Progenitor Oval Cells Increases Sensitivity to Apoptosis in Vitro Am J Pathol. May; 172(5): 1238-1247.

Ezzat, S.; Abdel-Hamid, A.; Eissa, SA.; Mokhtar, N.; Laabib, NA.; El-ghoroy, L.; Mikhail, NN.; Abdel-hamid, A.; Hifnawy, T.; Strickland, GT. and El-loffredo (2005): Association of pesticides, $\mathrm{HCV}, \mathrm{HBV}$ and hepatocelluar carcinoma in Egypt. Int. J. HygEnviron Health.; 208 (5): 329-39.

Factor, VM.; Seo, D.; Ishikawa, T.; Kaposi-Novak, P.; Marquardt, JU.; Andersen, JB.; Conner, EA. and Thorgeirsson, SS. (2010): Loss of c Met disrupts gene expression program required for $\mathrm{G} 2 / \mathrm{M}$ progression during liver regeneration in mice. PLoS One. Sep 16; 5(9). pii: e12739.

Ferlay, J.; Bray, F.; Pisani, P. and Parkin, DM. (2004): Cancer incidence, mortality and prevalence worldwide IARC cancer base No. 5 v 2.0 IARC press. Lyon.

Fritz Heidi; Deborah Kennedy; Dean Fergusson; Rochelle Fernandes; Kieran Cooley; Andrew Seely; Stephen Sagar; Raimond Wong and Dugald Seely mail (2011): Selenium and Lung Cancer: A Systematic Review and Meta Analysis. Plos one journal DOI: 10.1371/journal. pone. 0026259.

Helen W. Lane; Camille K. Tracey; Daniel Medina hennery, J.; Thompsn, I David Meeker and Stephen Kokoska (1984): Effect of an inorganic and organic from dietary selenium on promotional stages of mammary cracinogenesis in the rat cancer res 44: 28302806.

Gordin Maya;* MelaniaTesio; * Sivan Cohen;* Yael Gore;* FridaLantner; * Lin Leng; Richard Bucala, and Idit Shachar (2010): c-met and Its Ligand Hepatocyte Growth Factor/Scatter Factor Regulate Mature B Cell Survival in a Pathway Induced by CD74. Journal of immunology, 185: 2020-2031.

Kim, JH ${ }^{l}$; Hue, JJ; Kang, BS.; Park, H.; Nam, SY.; Yun, YW. and Kim, JS. (2011): Effects of selenium on colon carcinogenesis induced by azoxymethane and dextran sodium sulfate in mouse model with high-iron diet. Lab Anim Res. 2011 Mar; 27(1): 9-18.

London, WT. and McGlynn, KA. (2006): Liver Cancer. In: Schottenfeld D, Fraumeni Jr. J, eds. Cancer Epidemiology and Prevention. 3rd ed. New York: Oxford University Press; 763786.

Luger, D.; Dayan, M.; Zinger, H.; Liu, J.P. and Mozes, E. (2004): A peptide basedon the complementarity determining region 1 of a human monoclonal autoan-tibody ameliorates spontaneous and induced lupus manifestations in correlation with cytokine immunomodulation. J. Clin. Immunol. 24: 579-590.

Marquardt, JU ${ }^{1 .}$; Seo, D.; Gómez-Quiroz, LE.; Uchida, K.; Gillen, MC.; Kitade, M.; KaposiNovak, P.; Conner, EA.; Factor, VM. and Thorgeirsson, SS. (2012): Loss of c-met accelerates development of liver fibrosis in response to $\mathrm{CCl}(4)$ exposure through deregulation of multiple molecular pathways. Biochim BiophysActa. 2012 Jun; 1822(6): 942-51.

Minami, M. and Yoshikawa, H. (1979): Simplified assay method of superoxide dismutase activity of clinical use. Clin. Chem. Acta 92, 337-342.

Mizutani, H. (2007): Mechanism of DNA damage and apoptosis induced by anticancer drugs through generation of reactive oxygen species]. Yakugaku Zasshi; 127: 1837-42.

Navab, R.; Liu, J.; Seiden-Long, I.; Shih, W.; Li, M. and Bandarchi, B. et al. (2009): Cooverexpression of Met and hepatocyte growth factor promotes systemic metastasis in NCIH460 non-small cell lung carcinoma cells. Neoplasia11: 1292-1300.

Reitman, S. and Frankel, S.A. mer (1957): A colorimetric method for determination of serum glutamic oxalacetic and glutamic pyruvic transaminase J. Clin. Pathol. 28: 56.

Schumacker, PT. (2006): Reactive oxygen species in cancer cells: live by the sword, die by the sword. Cancer Cell;10: 175-6.

Shiota Goshi; Ken-ichiHarade; Masato Ishida; Yasushl Tomie; Misiko Okubo; Shunsuke katayana; Hiso Ito and Hiromaka Kawaokl (1999): Inhibition of hepatocellular carcinoma by glycyrrhizin in diethynitrosamine trated mice. Carcinogenesis v20 (1) pp59-63.

Simon, HU.; Haj-Yehia, A. and Levi-Schaffer, F. (2000): Role of reactive oxygen species (ROS) in apoptosis induction. Apoptosis 5:415-8.

Sinha, BK. and Mimnaugh, EG. (1990): Free radicals and anticancer drug resis- tance: oxygen free radicals in the mechanisms of drug cytotoxicity and resistance by certain tumors. Free Radic Biol Med; 8: 567-81.

Takami Taro; Pal Kaposi-Novak; Koichi Uchida; Luis, E.; Gomez-QUIROZ; Elizabeth A. 
Conner; Valentina M. Factor and Snorri S. Thorgeirsso (2007): loss of hepatocyte growth factor/c-metsignalling pathway accelerates early stages of $\mathrm{N}$-nitrosodiethylamine induced hepatocarcinogenesis cancer res 67(20): 984451.

Trusolino, L.; Bertotti, A. and Comoglio, P.M. (2010): MET signalling: principles and functions in development, organ regeneration and cancer. Nat Rev Mol Cell Biol11: 834848.
Venkateswaran, V.; Fleshner, NE. and Klotz, LH. (2004): Synergistic effect of vitamin E and selenium in human prostate cancer cell lines. Prostate Cancer Prostatic Dis.; 7: 54-6.

Xiao, G.H.; Jeffers, M.; Bellacosa, A.; Mitsuuchi, Y.; Vande Woude, G.F. and Testa, J.R. (2001): Anti-apoptotic signaling by hepatocyte growth factor/Met via the phosphatidylinositol 3kinase/Akt and mitogen-activated protein kinase pathways. Proc Natl Acad Sci USA98: 24.

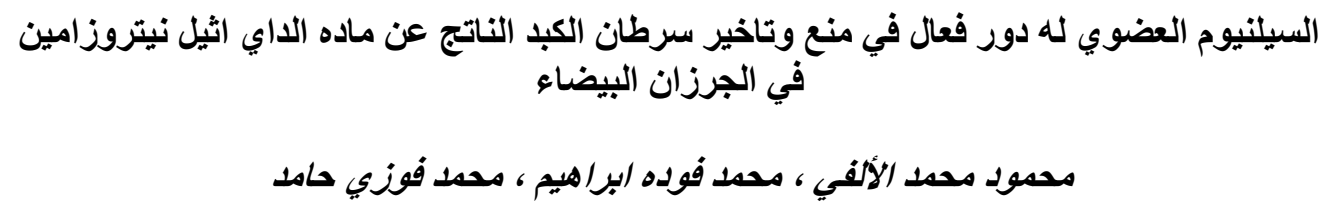

Email: dr_melalfym@yahoo.com

Assiut University web-site: $\underline{\text { www.aun.edu.eg }}$

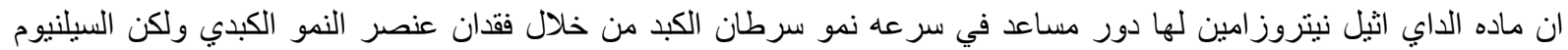

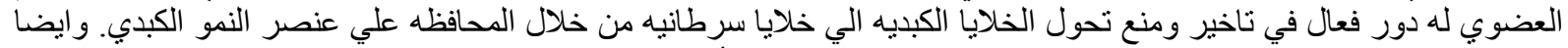

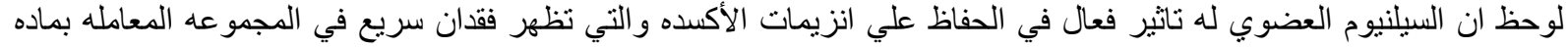

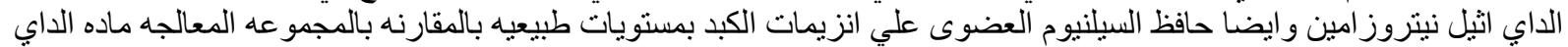

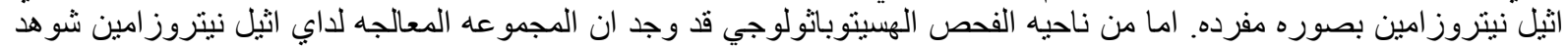

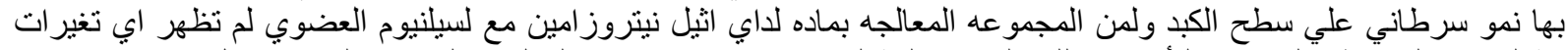

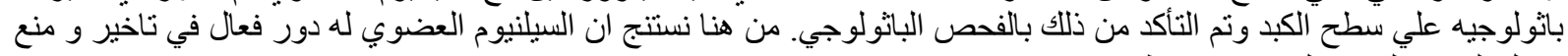
تحول الخلايا أكبديه الي خلايا سرطانيه. 